\title{
Intravenous busulfan-based conditioning with autologous stem cell transplantation for refractory B-cell lymphoma with central nervous system involvement
}

\author{
Mamiko Takahashi ${ }^{1}$, Ryohei Sumitani ${ }^{1}$, Taiki Hori' ${ }^{1}$, Jumpei Murai ${ }^{1}$, Shiyori Kawata ${ }^{1}$, Masahiro Oura ${ }^{1}$, \\ Kimiko Sogabe ${ }^{1}$, Takeshi Harada ${ }^{1}$, Shiro Fujii ${ }^{1}$, Hirokazu Miki ${ }^{2}$, Kumiko Kagawa ${ }^{1}$, Masahiro Abe ${ }^{1}$ and \\ Shingen Nakamura ${ }^{3}$
}

${ }^{1}$ Department of Hematology, Endocrinology and Metabolism, Institute of Biomedical Sciences, Tokushima University Graduate School, Tokushima, Japan, ${ }^{2}$ Division of Transfusion Medicine and Cell Therapy, Tokushima University Hospital, Tokushima, Japan, ${ }^{3}$ Department of Community Medicine and Medical Science, Tokushima University Graduate School of Biomedical Sciences, Tokushima, Japan

\begin{abstract}
The prognosis of relapsed or refractory lymphoma with central nervous system (CNS) involvement remains poor because of the lack of anticancer drugs with sufficient CNS penetration. [Case 1] A 65-year-old man was diagnosed with Stage IV mantle cell lymphoma. After two courses of chemotherapy and autologous hematopoietic stem cell (HSC) collection, urinary retention with fever developed. Cerebrospinal fluid analysis revealed leptomeningeal involvement, which was refractory to high-dose methotrexate therapy. Autologous peripheral blood stem cell transplantation (ASCT) was performed, followed by intravenous busulfan (ivBU), cyclophosphamide, and etoposide ; thereafter, no relapse has been detected for over six years. [Case 2] A 40-year-old woman with right lower hemiplegia was diagnosed with primary CNS lymphoma. Although four courses of highdose methotrexate therapy were administered, the cerebral tumor increased in size. HSCs were collected after methotrexate therapy, and ASCT was performed in addition to conditioning using ivBU, cyclophosphamide, and etoposide, followed by whole-brain and local boost irradiation. She achieved complete remission, but relapsed two years after ASCT. High-dose ivBU-containing conditioning regimens with ASCT may be useful for refractory B-cell lymphoma with CNS involvement. J. Med. Invest. 68:196-201, February, 2021
\end{abstract}

Keywords : busulfan, malignant lymphoma, central nervous system, autologous peripheral blood stem cell transplantation

\section{INTRODUCTION}

Involvement of the central nervous system by malignant lymphoma is a serious event for lymphoma patients. High-dose methotrexate (MTX)-based combination chemotherapy is commonly performed for patients with primary or secondary CNS invasion of malignant lymphoma in Japan. However, as they have a poor prognosis, new therapeutic strategies are needed.

We report two MTX resistant B-cell lymphoma patients with central nervous system invasion in whom autologous peripheral blood stem cell transplantation (ASCT) followed by intravenous busulfan (ivBU)-based conditioning chemotherapy was effective.

\section{CASE REPORT}

[Case 1] A 65-year-old man with a past history of glaucoma perceived right inguinal lymphadenopathy in X-6. Needle biopsy demonstrated the proliferation of abnormal lymphocytes positive for CD5, CD20, and cyclin D1, and negative for CD3 and CD10, and he was diagnosed with mantle cell lymphoma in January X. 18F-fluorodeoxyglucose-positron emission tomography/computed tomography (PET/CT) and bone marrow examination revealed the involvement of paraaortic, axillary, and right inguinal lymph nodes and bone marrow, and the disease was Stage

Received for publication May 20, 2020 ; accepted September 19, 2020.

Address correspondence and reprint requests to Shingen Nakamura, Department of Hematology, Endocrinology and Metabolism, Institute of Biomedical Sciences, Tokushima University Graduate School, Tokushima, Japan, 3-18-15 Kuramoto-cho, Tokushima, 770-8503, Japan and Fax : +81-88-633-7121.
IV based on the Ann-Arbor classification. He achieved a partial response after we administered two courses of rituximab plus fractionated cyclophosphamide, vincristine, doxorubicin, and dexamethasone alternating with high-dose methotrexate-cytarabine (R-hyper-CVAD / MTX-AraC), and collected his peripheral blood stem cells during the period of leucocyte recovery. High fever with bladder and rectal disturbance developed in June X. Cerebrospinal fluid (CSF) revealed lymphocytosis $(163 / \mu \mathrm{L})$ (cytology class IV) with increased protein $(129 \mathrm{mg} / \mathrm{dL})$. High signal in the spinal cord at the level of Th12 was noted on T2-weighted MRI, confirming leptomeningeal involvement of mantle cell lymphoma. Systemic MTX chemotherapy with an increased dose of $3.5 \mathrm{~g} / \mathrm{m}^{2}$ with repetitive intrathecal chemotherapy did not remove the lymphoma cells in the CSF. We administered ivBU $(3.2 \mathrm{mg} / \mathrm{kg} /$ day; days $-7,-6,-5$, and -4$)$, cyclophosphamide (CY) $(40 \mathrm{mg} / \mathrm{kg} /$ day ; days -3 and -2$)$, and etoposide (VP-16) $\left(200 \mathrm{mg} / \mathrm{m}^{2}\right.$; days -5 and -4$)$ as conditioning chemotherapy after receiving written informed consent, followed by ASCT with CD34-positive cells at $6.79 \times 10^{6} / \mathrm{kg}$ for residual lymphoma in the CNS (Figure 1). He developed no serious adverse events except for neutropenia and thrombocytopenia, with grade 4 oral mucositis and grade 3 febrile neutropenia. He achieved engraftment on day 10 for neutrophils, day 21 for reticulocytes, and day 21 for platelets. No relapse has been detected for over 7 years.

[Case 2] A 40-year-old woman developed incomplete right leg muscle weakness with numbness in July Y-1. Brain CT revealed a tumor of $2 \mathrm{~cm}$ in diameter at the left cingulate convolution with surrounding widespread edema (Figure 2). Stereotactic biopsy of the brain tumor in September Y-1 demonstrated diffuse proliferation of atypical large lymphocytes positive for bcl-2, MUM-1, and CD20, and negative for CD3, CD5, and CD10 on immunostaining. We diagnosed her with diffuse large B-cell lymphoma 
and performed intravenous high-dose MTX and Ara-C combination chemotherapy with rituximab, and intrathecal chemotherapy using MTX and Ara-C with dexamethasone. She achieved a partial response after three courses of chemotherapy, but the disease progressed with right leg paralysis. Autologous stem cell collection was performed after receiving written informed consent after the fifth course of R-MTX/Ara-C therapy, and high-dose chemotherapy followed by ASCT with CD34-positive cells at $4.93 \times 10^{6} / \mathrm{kg}$ was administered. The conditioning regimen was ivBU (3.2 mg/kg/day; days $-7,-6,-5$, and -4$)$, CY (60 $\mathrm{mg} /$ day ; days -3 and -2), and VP-16 (400 mg/m² ; day -4) (Figure $3)$. She developed no serious adverse events except for neutropenia and thrombocytopenia with grade 4 oral mucositis and grade 3 febrile neutropenia. She achieved engraftment on day 10 for neutrophils and day 20 for platelets. After engraftment, we performed whole-brain radiotherapy (36 Gy/18 fractions) followed by local boost irradiation (10 Gy/5 fractions). Two years and two months after ASCT, she developed a cerebeller lesion, which was suspected to be relapsed lymphoma, and died.

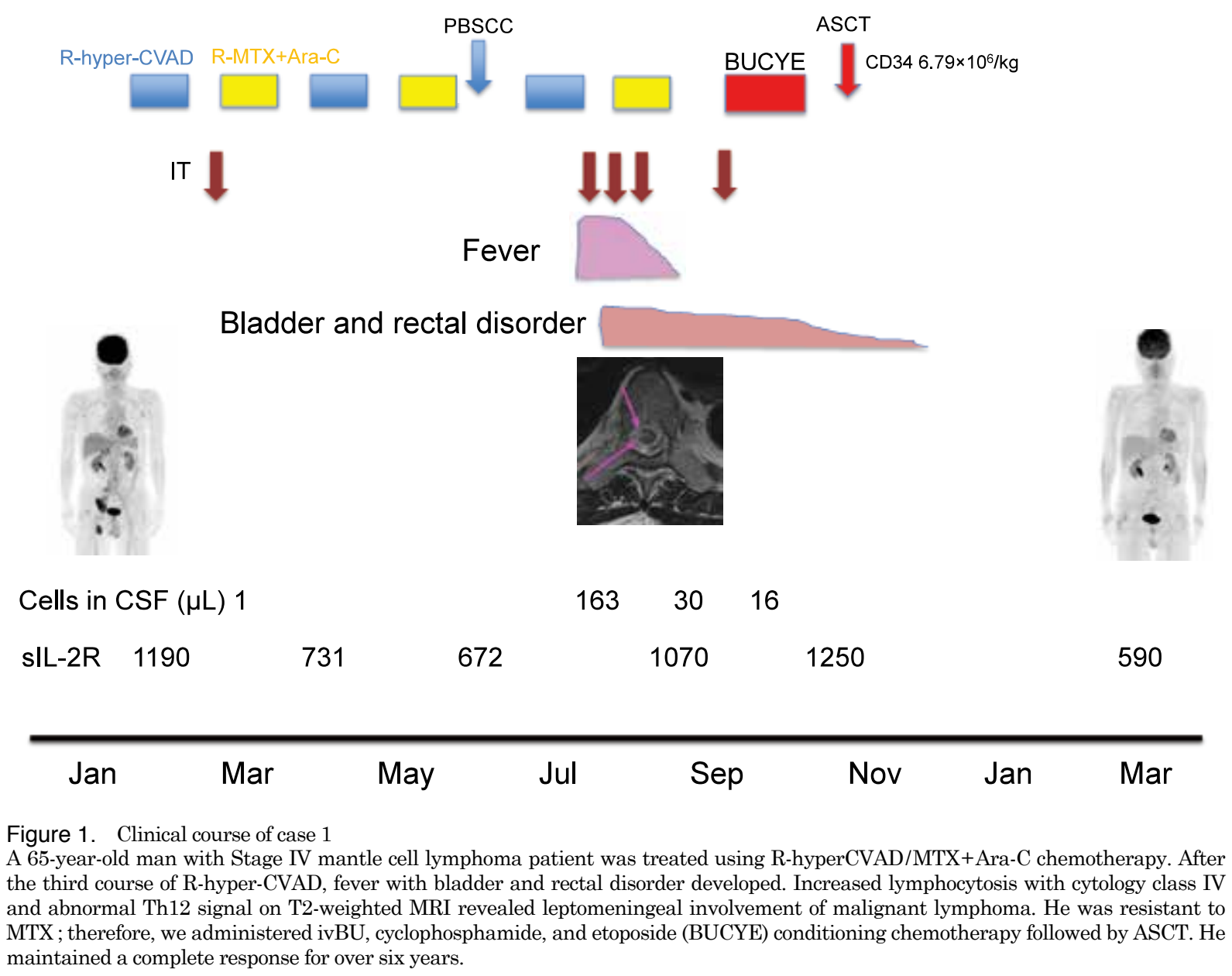

A

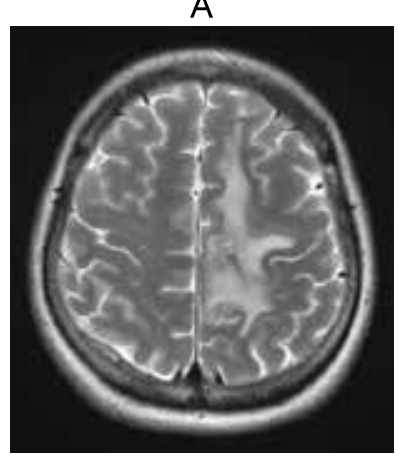

B

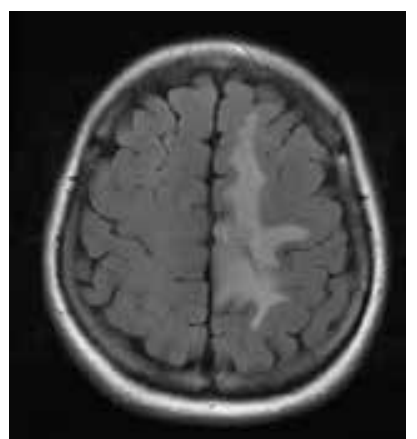

C

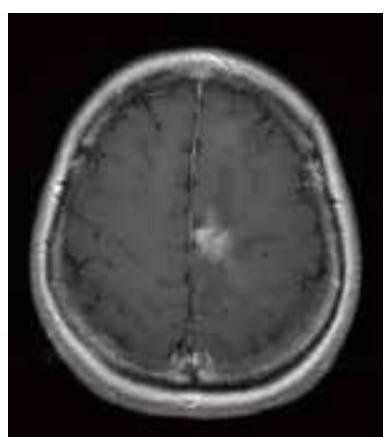

Figure 2. Brain MRI at initial presentation showed a left cingulate tumor surrounded by widespread edema on T2-weighted imaging (A), diffusion-weighted imaging (B), and gadolinium-enhanced T1-weighted imaging (C). 


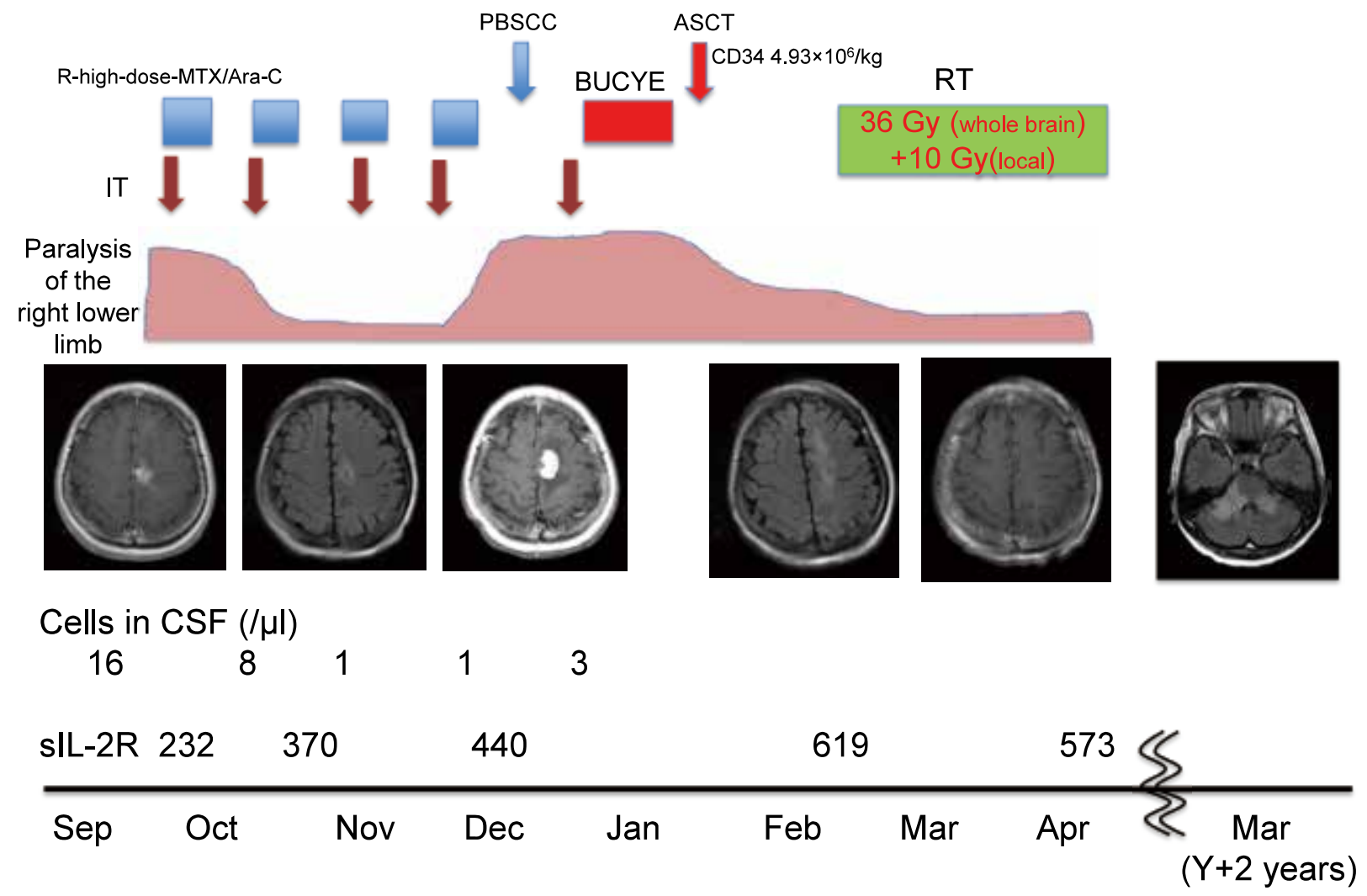

Figure 3. Clinical course of case 2

A 40-year-old woman with primary CNS lymphoma was treated using R-MTX + Ara-C chemotherapy. After three courses, she developed epilepsy with paralysis of the right lower limb. We administered ivBU, cyclophosphamide, and etoposide conditioning chemotherapy followed by ASCT. After engraftment, we performed whole-brain and local brain irradiation as consolidation therapy. She survived for two years and two months after ASCT.

\section{DISCUSSION}

We report two patients with relapsed or refractory B-cell lymphoma with CNS involvement in whom a conditioning regimen using ivBU, cyclophosphamide, and etoposide (BUCYE) followed by ASCT was effective. This study was approved by the internal review board of Tokushima University (permission number 3041).

Systemic chemotherapy using high-dose MTX, intrathecal chemotherapy, and whole-brain and/or local irradiation has been performed for malignant lymphoma with CNS involvement. However, its prognosis has not improved. In a historical lymphoma case series that included patients with secondary CNS involvement, the reported median survival was four months $(1$, 2). In primary CNS lymphoma, a primary refractory disease whereby there is an insufficient response to initial methotrexate therapy, similar to our case 2 , has a particularly poor prognosis, with a median survival of less than 2 months without additional treatment (3). Almost all anticancer drugs do not satisfactorily penetrate the blood brain barrier, and few drugs, such as MTX and Ara-C, which can relatively easily penetrate the CNS, have been approved for treating lymphoma in Japan. As a result, it is difficult to achieve good outcomes by ranimustine, VP-16, Ara-C, and melphalan, which is a commonly administered conditioning regimen (termed MEAM regimen) for relapsed lymphoma patients in Japan, because it does not penetrate the CNS. Thus, conditioning regimens using anticancer drugs that preferentially enter the CNS for ASCT have been employed abroad.
Thiotepa is an alkylating drug that has good CNS penetration, and has been reported to rapidly equilibrate in the lumbar and ventricular CSF in rhesus monkeys (4). Although thiotepa was available until 2009 in Japan, it was repurposed in 2019 for conditioning chemotherapy for ASCT with malignant lymphoma or pediatric solid cancer patients. Therefore, few alternative drugs for conditioning regimens of ASCT are available for adult malignant lymphoma patients with CNS involvement who are refractory/resistant to MTX and/or Ara-C.

$\mathrm{BU}$ is another alkylator and its penetration of the CNS is nearly equal to that of blood plasma (5). It is frequently used in conditioning regimens for allogeneic hematopoietic cell transplantation (6). There are several reports about ivBU-based conditioning regimens followed by ASCT for refractory or resistant malignant lymphoma with CNS involvement (Table 1). We found nineteen reports in which both thiotepa and ivBU were administered for primary or secondary CNS involvement by lymphoma as conditioning chemotherapy followed by ASCT (7-24), and BUCYE was administered in one report (25). The overall survival was relatively satisfactory in most reports. In addition, treatment-related mortality was not high in most reports, although the treatment-related mortality was $14.2 \%$ in one report, which was thought to be due to sepsis during neutropenia (7). We performed ASCT with a BUCYE conditioning regimen for two malignant lymphoma patients with CNS involvement who were resistant to MTX. Although we reduced the dose of VP-16 in case 1 , there were no adverse events except for neutropenia, grade 4 thrombocytopenia, and mucosal damage. There are few 
Table 1. Reported case of autologous stem cell transplantation for relapsed/refractory malignant lymphoma with central nervous system involvement.

TRM: treatment-related mortality, ND : not described, OS : overall survival, BU: busulfan, CY : cyclophosphamide, CNS : central nervous system, PCNSL : primary central nervous system lymphoma, NHL : non-Hodgkin's lymphoma.

\begin{tabular}{|c|c|c|c|c|c|c|}
\hline $\begin{array}{c}\text { Number } \\
\text { of } \\
\text { patients }\end{array}$ & Disease & $\begin{array}{l}\text { Conditioning } \\
\text { regimen }\end{array}$ & TRM & CR rate & os & Reference \\
\hline 7 & Primary PCNSL & Thiotepa/BU/CY & $14.2 \%$ & $100 \%$ & Median 24 months & 7 \\
\hline 16 & Primary PCNSL & Thiotepa/BU & $0 \%$ & $68.8 \%$ & 2-year OS 48\% & 8 \\
\hline 43 & Refractory NHL & Thiotepa/BU/CY & $0 \%$ & ND & $\begin{array}{l}\text { Median } 18.3 \\
\text { months }\end{array}$ & 9 \\
\hline 11 & Primary PCNSL & BUCYE & $0 \%$ & $90.9 \%$ & $\begin{array}{c}\text { 2-year OS } \\
88.9 \%\end{array}$ & 25 \\
\hline 21 & Primary PCNSL & Thiotepa/BU/CY & $14.2 \%$ & ND & 5 -year OS $44 \%$ & 10 \\
\hline 32 & Refractory NHL & Thiotepa/BU/CY & $3 \%$ & ND & 1-year OS 93\% & 11 \\
\hline 79 & R/R PCNSL & Thiotepa/BU/CY & $7.6 \%$ & $83.5 \%$ & 5 -year OS 51\% & 12 \\
\hline 16 & Refractory PCNSL & Thiotepa/BU & $12.5 \%$ & $75 \%$ & 1-year OS 62.5\% & 13 \\
\hline 18 & R/R PCNSL & Thiotepa/BU & $0 \%$ & $83.3 \%$ & ND & 14 \\
\hline 15 & $\begin{array}{l}\text { R/R primary or secondary } \\
\text { CNS lymphoma }\end{array}$ & Thiotepa/BU/CY & $0 \%$ & $86.7 \%$ & 3-year OS 93\% & 15 \\
\hline 29 & $\begin{array}{l}\text { R/R Primary or secondary } \\
\text { CNS lymphoma }\end{array}$ & Thiotepa/BU/CY & $0 \%$ & $100 \%$ & 2-year OS 93\% & 16 \\
\hline 12 & $\begin{array}{l}\text { R/R secondary CNS } \\
\text { lymphoma }\end{array}$ & Thiotepa/BU & $0 \%$ & ND & 1-year OS $75 \%$ & 17 \\
\hline 26 & Primary PCNSL & Thiotepa/BU/CY & $7.7 \%$ & $81 \%$ & 2 -year OS $81 \%$ & 18 \\
\hline 23 & $\begin{array}{c}\text { Primary or relapsed CNS } \\
\text { lymphoma }\end{array}$ & Thiotepa/BU & $8.7 \%$ & $87 \%$ & 2-year OS 76.1\% & 19 \\
\hline 20 & Primary NHL & Thiotepa/BU/CY & $0 \%$ & ND & 4 -year OS $82 \%$ & 20 \\
\hline 15 & $\begin{array}{l}\text { R/R Secondary CNS } \\
\text { lymphoma }\end{array}$ & $\mathrm{BU} / \mathrm{CY}$ & $0 \%$ & ND & 1 -year OS $25 \%$ & 21 \\
\hline 43 & Primary and R/R PCNSL & Thiotepa/BU/CY & $7 \%$ & ND & 1 -year OS $87 \%$ & 22 \\
\hline 46 & Primary PCNSL & Thiotepa/BU/CY & $0 \%$ & ND & 2-year OS 95\% & 23 \\
\hline 34 & R/R secondary lymphoma & $\begin{array}{c}\text { Semustine, } \\
\text { hydroxyurea,BU/CY }\end{array}$ & $2.9 \%$ & $64.7 \%$ & 2 -year OS $81 \%$ & 24 \\
\hline
\end{tabular}

reports on ASCT for malignant lymphoma in Japan, but ivBU is widely administered for allogeneic stem cell transplantation in ivBU-based conditioning regimens. Therefore, ivBU-based conditioning regimens for ASCT are tolerable for lymphoma patients. As a point of benefit of ivBU-based conditioning chemotherapy, primary refractory for MTX in primary CNS lymphoma has a particularly poor prognosis with a median survival of less than 2 months, and salvage whole brain radiation also has a poor prognosis with median survival from initiation of whole brain radiotherapy reported to be 10.9 months $(3,26)$. Because case 2 survived 26 months after ASCT, ivBU-based chemotherapy may have contributed to extending her survival.

The sensitivity of lymphoma to BU is of concern. BU is used only for conditioning, and not as induction chemotherapy for malignant lymphoma. Therefore, we cannot confirm the sensitivity of BU before ASCT in clinical settings. However, many studies reported good survival of malignant lymphoma by ivBU-based conditioning followed by autologous or allogeneic transplantation $(6,25,27)$. In addition, the IC50 of BU for Raji cell lines were 0.9-1.2 $\mu \mathrm{M}$, which are similar to that of melphalan in vitro (28). In clinical practice, we administer ivBU once per day and not fractionated to increase its concentration in the CSF as much as possible. It was previously reported that once-daily intravenous administration achieved a four-fold higher Cmax than four- times-daily administration, although the AUC and t1/2 were similar (29). However, it is unknown whether once-daily administration of ivBU is more effective for malignant lymphoma with CNS involvement than four-times-daily administration. Thus, more clinical cases are warranted.

In conclusion, a high-dose ivBU-based conditioning regimen with ASCT may be useful for refractory lymphoma with CNS involvement.

\section{CONFLICT OF INTERESTS}

The authors declare no conflicts of interest associated with this manuscript.

\section{REFERENCES}

1. Boehme V, Zeynalova S, Kloess M, Loeffler M, Kaiser U, Pfreundschuh M, Schmitz N : Incidence and risk factors of central nervous system recurrence in aggressive lymphoma--a survey of 1693 patients treated in protocols of the German High-Grade Non-Hodgkin's Lymphoma Study Group (DSHNHL). Ann Oncol 18(1) : 149-157, 2007 
2. Zinzani PL, Magagnoli M, Frezza G, Prologo G, Gherlinzoni F, Bendandi M, Albertini P, Babini L, D’Alessandro R, Tura $\mathrm{S}$ : Isolated central nervous system relapse in aggressive non-Hodgkin's lymphoma : the Bologna experience. Leuk Lymphoma 32(5-6) : 571-576, 1999

3. Graham MS, DeAngelis LM : Improving outcomes in primary CNS lymphoma. Best practice \& research Clinical haematology 31(3) : 262-269, 2018

4. Strong JM, Collins JM, Lester C, Poplack DG : Pharmacokinetics of intraventricular and intravenous N,N',N"-triethylenethiophosphoramide (thiotepa) in rhesus monkeys and humans. Cancer Res 46(12 Pt 1) : 6101-6104, 1986

5. Hassan M, Ehrsson H, Smedmyr B, Totterman T, Wallin I, Oberg G, Simonsson B : Cerebrospinal fluid and plasma concentrations of busulfan during high-dose therapy. Bone Marrow Transplant 4(1) : 113-114, 1989

6. Ciurea SO, Andersson BS : Busulfan in hematopoietic stem cell transplantation. Biol Blood Marrow Transplant 15(5) : 523-536, 2009

7. Cheng T, Forsyth P, Chaudhry A, Morris D, Gluck S, Russell JA, Stewart DA : High-dose thiotepa, busulfan, cyclophosphamide and ASCT without whole-brain radiotherapy for poor prognosis primary CNS lymphoma. Bone Marrow Transplant 31(8) : 679-685, 2003

8. Montemurro M, Kiefer T, Schuler F, Al-Ali HK, Wolf HH, Herbst R, Haas A, Helke K, Theilig A, Lotze C, Hirt C, Niederwieser D, Schwenke M, Kruger WH, Dolken G : Primary central nervous system lymphoma treated with highdose methotrexate, high-dose busulfan/thiotepa, autologous stem-cell transplantation and response-adapted wholebrain radiotherapy: results of the multicenter Ostdeutsche Studiengruppe Hamato-Onkologie OSHO-53 phase II study. Ann Oncol 18(4) : 665-671, 2007

9. Santos EC, Sessions J, Hutcherson D, Flowers C, Langston A, Waller EK : Long-term outcome of Hodgkin disease patients following high-dose busulfan, etoposide, cyclophosphamide, and autologous stem cell transplantation--a similar experience. Biol Blood Marrow Transplant 13(6) : 746-747, 2007

10. Alimohamed N, Daly A, Owen C, Duggan P, Stewart DA : Upfront thiotepa, busulfan, cyclophosphamide, and autologous stem cell transplantation for primary CNS lymphoma : a single centre experience. Leuk Lymphoma 53(5) : 862-867, 2012

11. Cote GM, Hochberg EP, Muzikansky A, Hochberg FH, Drappatz J, McAfee SL, Batchelor TT, LaCasce AS, Fisher DC, Abramson JS, Armand P, Chen YB: Autologous stem cell transplantation with thiotepa, busulfan, and cyclophosphamide (TBC) conditioning in patients with CNS involvement by non-Hodgkin lymphoma. Biol Blood Marrow Transplant 18(1) : 76-83, 2012

12. Soussain C, Choquet S, Fourme E, Delgadillo D, Bouabdallah K, Ghesquieres H, Damaj G, Dupriez B, Vargaftig J, Gonzalez A, Houillier C, Taillandier L, Hoang-Xuan K, Leblond $\mathrm{V}$ : Intensive chemotherapy with thiotepa, busulfan and cyclophosphamide and hematopoietic stem cell rescue in relapsed or refractory primary central nervous system lymphoma and intraocular lymphoma: a retrospective study of 79 cases. Haematologica 97(11) : 1751-1756, 2012

13. Kiefer T, Hirt C, Spath C, Schuler F, Al-Ali HK, Wolf HH, Herbst R, Maschmeyer G, Helke K, Kessler C, Niederwieser D, Busemann C, Schroeder H, Vogelgesang S, Kirsch M, Montemurro M, Kruger WH, Dolken G : Long-term follow-up of high-dose chemotherapy with autologous stemcell transplantation and response-adapted whole-brain radiotherapy for newly diagnosed primary CNS lymphoma: results of the multicenter Ostdeutsche Studiengruppe Hamatologie und Onkologie OSHO-53 phase II study. Ann Oncol 23(7) : 1809-1812, 2012

14. Choi MK, Kang ES, Kim DW, Ko YH, Seok H, Park JH, Pyo DH, Hoon Lim D, Kim SJ, Kim WS : Treatment outcome of relapsed/refractory primary central nervous system diffuse large B-cell lymphoma : a single-center experience of autologous stem cell transplantation. Int J Hematol 98(3) : 346354,2013

15. Welch MR, Sauter CS, Matasar MJ, Faivre G, Weaver SA, Moskowitz CH, Omuro AM : Autologous stem cell transplant in recurrent or refractory primary or secondary central nervous system lymphoma using thiotepa, busulfan and cyclophosphamide. Leuk Lymphoma 56(2) : 361-367, 2015

16. Chen YB, Batchelor T, Li S, Hochberg E, Brezina M, Jones S, Del Rio C, Curtis M, Ballen KK, Barnes J, Chi AS, Dietrich J, Driscoll J, Gertsner ER, Hochberg F, LaCasce AS, McAfee SL, Spitzer TR, Nayak L, Armand P : Phase 2 trial of high-dose rituximab with high-dose cytarabine mobilization therapy and high-dose thiotepa, busulfan, and cyclophosphamide autologous stem cell transplantation in patients with central nervous system involvement by non-Hodgkin lymphoma. Cancer 121(2) : 226-233, 2015

17. Lee MY, Kim HS, Lee JY, Lim SH, Kang ES, Ko YH, Kim SJ, Kim WS : Efficacy and feasibility of autologous stem cell transplantation in patients with diffuse large Bcell lymphoma with secondary central nervous system involvement. Int J Hematol 102(6) : 678-688, 2015

18. Omuro A, Correa DD, DeAngelis LM, Moskowitz CH, Matasar MJ, Kaley TJ, Gavrilovic IT, Nolan C, Pentsova E, Grommes CC, Panageas KS, Baser RE, Faivre G, Abrey LE, Sauter CS : R-MPV followed by high-dose chemotherapy with TBC and autologous stem-cell transplant for newly diagnosed primary CNS lymphoma. Blood 125(9) : 14031410,2015

19. Oh DH, Chua N, Street L, Stewart DA : Treatment of patients with secondary central nervous system lymphoma with high-dose busulfan/thiotepa-based conditioning and autologous stem cell transplant. Leuk Lymphoma 57(1) : 28 33,2016

20. Qualls D, Sullivan A, Li S, Brunner AM, Collier K, Hochberg E, Armand P, Batchelor TT, Chen YB, DeFilipp Z : Highdose Thiotepa, Busulfan, Cyclophosphamide, and Autologous Stem Cell Transplantation as Upfront Consolidation for Systemic Non-Hodgkin Lymphoma With Synchronous Central Nervous System Involvement. Clinical lymphoma, myeloma \& leukemia 17(12) : 884-888, 2017

21. Doorduijn JK, van Imhoff GW, van der Holt B, Schouten HC, Schaafsma MR, MacKenzie MA, Baars JW, Kersten MJ, Lugtenburg PJ, van den Bent MJ, Enting RH, Spoelstra FM, Poortmans P, Bromberg JEC : Treatment of secondary central nervous system lymphoma with intrathecal rituximab, high-dose methotrexate, and R-DHAP followed by autologous stem cell transplantation : results of the HOVON 80 phase 2 study. Hematol Oncol 35(4) : 497-503, 2017

22. Scordo M, Morjaria SM, Littmann ER, Bhatia A, Chung HH, Maloy M, DeAngelis LM, Giralt SA, Taur Y, Sauter CS : Distinctive Infectious Complications in Patients with Central Nervous System Lymphoma Undergoing Thiotepa, Busulfan, and Cyclophosphamide-conditioned Autologous Stem Cell Transplantation. Biol Blood Marrow Transplant 24(9) : 1914-1919, 2018

23. DeFilipp Z, Li S, El-Jawahri A, Armand P, Nayak L, Wang N, Batchelor TT, Chen YB: High-dose chemotherapy with thiotepa, busulfan, and cyclophosphamide and autologous 
stem cell transplantation for patients with primary central nervous system lymphoma in first complete remission. Cancer 123(16) : 3073-3079, 2017

24. Hyung J, Hong JY, Yoon DH, Kim S, Park JS, Park CS, Lee SW, Kim JH, Ryu JS, Huh J, Suh C: Thiotepa, busulfan, and cyclophosphamide or busulfan, cyclophosphamide, and etoposide high-dose chemotherapy followed by autologous stem cell transplantation for consolidation of primary central nervous system lymphoma. Ann Hematol 98(7) : 16571664,2019

25. Yoon DH, Lee DH, Choi DR, Sohn BS, Kim S, Kim SW, Lee JS, Lee SW, Huh J, Suh C : Feasibility of BU, CY and etoposide (BUCYE), and auto-SCT in patients with newly diagnosed primary CNS lymphoma : a single-center experience. Bone Marrow Transplant 46(1) : 105-109, 2011

26. Nguyen PL, Chakravarti A, Finkelstein DM, Hochberg FH, Batchelor TT, Loeffler JS : Results of whole-brain radiation as salvage of methotrexate failure for immuno- competent patients with primary CNS lymphoma. J Clin Oncol 23(7) : 1507-1513, 2005

27. Shin HJ, Lee WS, Lee HS, Kim H, Lee GW, Song MK, Kim JS, Yhim HY, Chung JS : Busulfan-containing conditioning regimens are optimal preparative regimens for autologous stem cell transplant in patients with diffuse large B-cell lymphoma. Leuk Lymphoma 55(11) : 2490-2496, 2014

28. Teicher BA, Cucchi CA, Lee JB, Flatow JL, Rosowsky A, Frei E, 3rd : Alkylating agents : in vitro studies of cross-resistance patterns in human cell lines. Cancer Res 46(9) : 4379-4383, 1986

29. Ryu SG, Lee JH, Choi SJ, Lee JH, Lee YS, Seol M, Hur EH, Lee SH, Bae KS, Noh GJ, Lee MS, Yun SC, Han SB, Lee $\mathrm{KH}$ : Randomized comparison of four-times-daily versus once-daily intravenous busulfan in conditioning therapy for hematopoietic cell transplantation. Biol Blood Marrow Transplant 13(9) : 1095-1105, 2007 